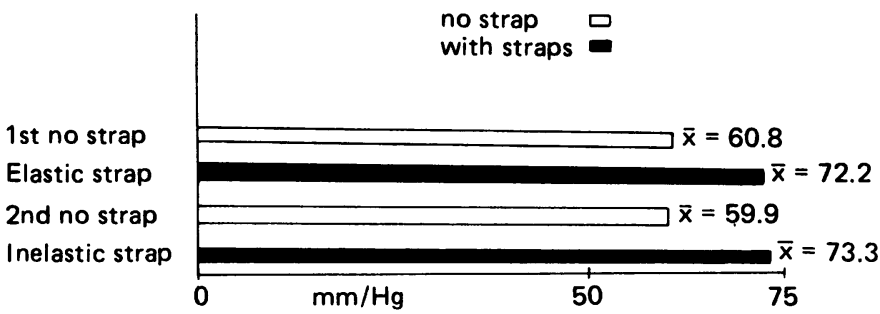

Fig. 3: Bar chart representation of the means of grip strength readings from Table I.

TABLE I

Effects of forearm strap on pain-free grip strengths in 27 epicondylitis patients.

Effect of strap

Grip strength increase

Grip strength no change

Grip strength decreased

\begin{tabular}{cc}
\multicolumn{2}{c}{ Elastic } \\
Number & Proportion \\
22 & $81 \%$ \\
2 & $7 \%$ \\
3 & $11 \%$
\end{tabular}

Patients with no change on both straps Patients with decrease on both straps Patients with increase on both straps Patients with increase on one strap

\begin{tabular}{cc}
\multicolumn{2}{c}{ Inelastic } \\
Number & Proportion \\
22 & $81 \%$ \\
4 & $15 \%$ \\
1 & $4 \%$ \\
$=$ & 1 \\
$=$ & 1 \\
$=$ & $19(70 \%)$ \\
$=$ & $4(15 \%)$
\end{tabular}

no increase in maximum grip strength when wearing the straps.

\section{DISCUSSION}

The results of this study indicate that the use of forearm straps will increase pain-free grip strength in tennis elbow patients. Since there is a strong correlation between increased painfree grip strength and symptomatic improvement during recovery from tennis elbow (Burton, 1984), it is reasonable to suppose that forearm straps may have some therapeutic value.

The mode of action of tennis elbow straps is supposedly that they protect the common extensor origin from further strain, thus allowing the inflammatory reaction to subside and a healing of the lesion to ensue. Whilst this may be true, the mechanical support offered did not increase grip strength in the healthy subjects. An alternative mode of action is that of a reflex reduction in pain allowing greater grip strength; though this does not entirely explain the increase found over time, whilst patients recovered in a clinical study, where the measurements were taken without the straps in place (Burton, 1984). It would seem, from the available evidence, that any therapeutic value of forearm straps would arise from a reflexlymediated pain reduction initially, combined with mechanical support to the common extensor origin to permit healing whilst maintaining function.

There remains, of course, a need to demonstrate that these forearm straps are an effective part of the long term treatment of tennis elbow and clinical trials are justified by the current lack of a universally accepted treatment for this condition.

\section{CONCLUSION}

Strap devices, worn around the upper forearm under moderate tension, are capable of increasing pain-free grip strength in tennis elbow patients. No evidence is apparent, from this study, to suggest a difference between elastic and inelastic straps. Though sound clinical trials are required, there is reason to suppose that the straps could be a useful part of the management of the condition.

\section{ACKNOWLEDGEMENTS}

Thanks are due to the practitioners who collected the data and to Cumbria Orthopaedic and Doylecroft Ltd. for providing the straps.

\section{References}

Binder, A. I. and Hazleman, B. L., 1983 "Lateral humeral epicondy litis - a study of natural history and the effects of conservative therapy". Br.J.Rheumatol. 22: 73-76.

Burton, A. K. and Edwards, V. A., 1982 "Electromyography and tennis elbow straps". Br.Osteopath.J. 14: 83-86.

Burton, A. K., 1984 "Grip strength as an objective clinical assessment in lateral epicondylitis". Br.Osteopath.J. 16: 6-10.

Carroll, R, 1981 "Tennis elbow: incidence in local league players". Brit.J.Sports Med. 15: 250-256.

Day, B. H., Govindasamy, N. and Patnaik, R., 1978 "Corticosteroid injections in the treatment of tennis elbow". Practitioner 220 459-462.

Fernando, M U. and Robertson J. C. 1982 "Grip strength in the healthy". Rheumatol.Rehabil. 21: 179-181.

Froimson, A. I., 1971 "Treatment of tennis elbow with forearm support band". J.Bone Jt.Surg. 53-A: 183-184.

Gruchow, H. W. and Pelletier, D., 1979 "An epidemiologic study of tennis elbow: incidence, recurrence and effectiveness of prevention strategies". Am.J.Sports Med. 7: 234-238.

Ilfield, F. W. and Field, S. M., 1966 "Treatment of tennis elbow: use of a special brace". JAMA 195: 67-70.

Morris, $H, 1882$ "The lawn tennis elbow". Lancet 2: 133-4.

Nirschl, R. P. 1974 "Discussion of Bernhang et als' paper on tennis elbow: a biomechanical approach". J.Sports Med.\& Phys.Fit. 2: 258-259.

Title:

Editors:

Publisher:

\title{
SURGERY OF THE SHOULDER
}

\section{BOOK REVIEW}

$$
\begin{aligned}
& \text { C. V. Mosby (Blackwell, Oxford for U.K.) } \\
& \text { Price: } £ 46 \quad 348 \text { pages Index }
\end{aligned}
$$

Many figs. Tables $X$-rays

This book is in fact a series of lectures from the Second International Shoulder Conference of 1983. An obvious consequence is the disparity of style and language, and a bewildering number of contributors. Only those with some knowledge of the subject will be able to pick the senior author; a frequent necessity if the value of the paper is to be judged.

However, the book is well sub-divided into sections and within these sections there are ample up-to-date opinions. The reade should have no difficulty in reinforcing his own prejudices but with selective reading! It is necessary to read a whole section at one time.

On the whole this is a useful well published collection of up-to-date opinions that is best read a month before rather than the day before dealing with the problem. 